\title{
De Moisés Ville a Madrid: Los argentinos- judíos y la solidaridad con el bando republicano durante la Guerra Civil Española
}

Raanan Rein

Universidad de Tel Aviv, Israel

Fecha de recepción: 16 de marzo de 2020. Fecha de aceptación: 22 de mayo de 2020.

\section{Resumen $^{1}$}

El número de voluntarios judíos que se enrolaron en las Brigadas Internacionales para defender a la República española de los rebeldes nacionalistas fue muy elevado. Su sobrepresencia se notaba entre los voluntarios norteamericanos, así como entre los que vinieron de Polonia, Francia e Inglaterra. Este es también el caso argentino. Tras una breve discusión sobre las repercusiones de la Guerra Civil española en la Argentina, este trabajo se centra en argentinos-judíos que se presentaron como voluntarios para combatir el fascismo en suelo ibérico. Hay una necesidad urgente de llenar importantes lagunas en la historiografía de los argentinos-judíos, especialmente en lo que se refiere a aquellos no afiliados a las instituciones comunitarias, y en la historiografía de la izquierda argentina en general. Como judíos, abrigaban una preocupación adicional sobre las viles consecuencias del fascismo en general y del nazismo en particular. Desde su punto de vista, el apoyo brindado a la rebelión nacionalista por la Alemania de Hitler y la Italia de Mussolini era causa de gran alarma. Al mismo tiempo, manifestar tal solidaridad transnacional con la España asediada era también una forma de promover causas sociales y étnicas en Argentina

1 Una versión anterior de este artículo se publicó en la revista Investigaciones y Ensayos, Núm. 61 (2014), 405-425. Algunas de las ideas planteadas aquí fueron incluidas en el capítulo "Desafiando la política oficial: el antifranquismo en Argentina. 1936-1949" (Rein, 2016). 


\title{
From Moisés Ville to Madrid: Jewish Argentines and solidarity with republicans during Spanish Civil War
}

\begin{abstract}
The number of Jews among the international volunteers who went to Spain to defend the Republc and joined the International Brigades was very high. There was a disproportionate representation of Jews among the volunteers from the United States, as well from Poland, France, or England. This was also the case of Argentina. Following a brief discussion of the Spanish Civil War's repercussions in Argentina, this paper focuses on the history of Jewish-Argentine who volunteered to fight Fascism in the Iberian Peninsula. There is an urgent need to fill a lacuna iin the histoiography of Jewish-Argentine experineces, especially of non-affilated Jews, and of the Argentine left in general. As Jews, these volunteers had an additional concern over the the dangers of Fascism in general and Nazism i particular. From their point of view, the support given to the nationalist rebellion in Spain by Hitler and Mussolini was a cause for alarm. Furtheremore, expressing a transnational solidarity with the besieged Republic was also a form of promoting social and ethnic goals in Argentina.
\end{abstract}

Keywords: Argentina, Jews, Spanish Civil War, Mika Feldman, Gregorio Bermann.

El poeta argentino-judío Juan Gelman, que mencionaba a menudo recuerdos de su infancia en el barrio porteño de Villa Crespo, dijo en una entrevista concedida al diario La Nación:

Yo tenía seis o siete años cuando empezó la guerra, y fue un fenómeno curioso, porque a buena parte de la gente le atrajo del lado republicano. Recuerdo cómo iba todas las noches a la esquina a comprar el diario Crítica para mi papá, que lo esperaba ansioso para seguir el desarrollo de la guerra, o cómo, con los demás chicos del barrio, juntábamos el papel de estaño de los chocolates porque creíamos que con esos papelitos fundidos se harían balas para los republicanos. ${ }^{2}$ 
Por su parte, el periodista Jacobo Timerman, en su famoso libro Preso sin nombre, celda sin número, rememora cómo, en 1937, su grupo de jóvenes sionistas-socialistas intentó defenderse de nacionalistas locales, cuando expresaban su apoyo a los republicanos:

Había que recorrer en pequeños grupos, las calles del barrio judío, el Once, donde vivíamos y donde se encontraba nuestra sede, y vigilar que los grupos fascistas y antisemitas no ensuciaran las paredes de las sinagogas, de las escuelas, no escribieran "Haga patria, mate un judío" o no improvisaran pequeñas tribunas donde frente a los cafés judíos lanzaban sus arengas contra los mismos judíos. Ahí estábamos nosotros, con nuestras pesadas paletas de ping-pong, de madera en esa época, y nos lanzábamos contra los fascistas hasta que dos o tres policías, aburridos, nos separaban y se llevaban a uno o dos jóvenes a la comisaría cercana (Timerman, 1982, 115).

En lo que se refería a España contó Timerman:

[...] los jóvenes del Hashomer Hatzair asistíamos a los mítines de solidaridad con la España republicana, con la España heroica del Ilanto, cuando aprendíamos los poemas de Pablo Neruda, de Louis Aragon, de Paul Eluard, de Stephen Spender, y nos conmovíamos con el "No pasarán" de Upton Sinclair o los artículos de llya Ehrenburg (Timerman, 1982, 117).

Como argentinos-judíos, Gelman, Timerman y miles de otros inmigrantes y sus descendientes nacidos ya en Argentina claramente luchaban contra las expresiones locales de fascismo y antisemitismo y, por consiguiente, también apoyaban a la República Española. Por ello, entre los residentes del Once y Villa Crespo, los dos barrios porteños más identificados con la colectividad judía porteña, la división fue entre quienes apoyaban la lucha antifranquista y aquellos que, por una u otra razón, permanecieron indiferentes al drama español. En esos espacios judíos no se podía encontrar a alguien que apoyara la rebelión nacionalista liderada por el Caudillo.

Los que apoyaban a la República no lo hacían necesariamente por una identificación ideológica con los partidos de izquierda en la península ibérica. Como judíos, abrigaban una preocupación adicional sobre las viles consecuencias del fascismo en general y del nazismo en particular. Desde su punto de vista, el apoyo brindado a la rebelión nacionalista por la Alemania de Hitler y la Italia de Mussolini era causa de gran alarma. Al mismo tiempo, manifestar tal solidaridad transnacional con la España asediada era también una forma de promover causas sociales y étnicas en 
el país. Después de la breve experiencia traumática que supuso la dictadura de José Félix Uriburu (1930-1932), la solidaridad con España fungía incluso como recurso político para luchar contra el fascismo en Argentina. La experiencia judeoargentina funciona aquí entonces como un prisma, a través del cual podemos discutir la relación entre la solidaridad transnacional y las formas en las que distintos grupos sociales se organizaron para promover cambios políticos y sociales (Gould, 2007; Smith and Johnston, 2002). Ésta incluye a los argentinos de origen judío en las geografías de la solidaridad transnacional de los años 30, por lo que su estudio aporta una dimensión étnica a una movilización política de fines transnacionales.

Tras una breve discusión sobre las repercusiones de la Guerra Civil española en la Argentina, este trabajo se centra en argentinos-judíos que se presentaron como voluntarios para combatir el fascismo en suelo ibérico. Hay una necesidad urgente de llenar importantes lagunas en la historiografía de los argentinos-judíos, especialmente en lo que se refiere a aquellos no afiliados a las instituciones comunitarias. Buena parte de la literatura existente sobre las vivencias judías en Argentina se ha centrado en miembros de instituciones o comunidades organizadas (Avni, 2002), y por lo tanto han ignorado a los voluntarios mencionados, la mayoría de los cuales se identificaba con el Partido Comunista Argentino (PCA), que ya en 1921 creó su sección judía, u otras corrientes de izquierda no-sionista. La historiografía argentina de las reacciones al conflicto español ha mostrado la misma actitud de olvido hacia estos argentinos-judíos. ${ }^{3}$ Esto guarda relación con el hecho de que numerosos intelectuales en casi toda América Latina rechazan la etnicidad como categoría analítica importante, excepto si se refiere a pueblos originarios/indígenas o de afrodescendientes. Además, buena parte de la historiografía sobre los partidos y movimientos de izquierda ha sido producida por intelectuales y académicos de izquierda, algunos de los cuales parecen sentirse incómodos cuando se trata de destacar la crucial presencia judía en estos marcos, no solamente durante la primera mitad del siglo XX.

\section{La sobrepresencia judía en las Brigadas Internacionales}

Para analizar este fenómeno de los voluntarios internacionales desde una perspectiva global, hay que tener en cuenta que el número de voluntarios judíos que se enrolaron en las Brigadas Internacionales para defender a la República española de los rebeldes nacionalistas fue muy elevado. Según

3 Un primer intento de recuperar su memoria es el libro de Boragina y Sommaro, 2016. 
la mayor parte de las estimaciones, el número de los voluntarios extranjeros, llegados desde unos 50 países, no superó los 40.000 (Jackson, 1986; Rodríguez de la Torre, 2006; Hurtado, 2013; Sánchez Cervelló y Agudo Blanco, 2015; Claret, 2016). Entre ellos el número de voluntarios judíos osciló entre 4.000 y 8.00o. Resulta difícil establecer una estimación más precisa acerca del número de los voluntarios de origen judío, ya que estuvieron diseminados entre las diversas unidades nacionales, con la excepción de aquellos que combatieron en la compañía "Naftali Botwin”, llamada así en homenaje al comunista polaco- judío que había sido ejecutado por el gobierno autoritario de Józef Klemens Pilsudski en 1925 (Zaagsma, 2017; Lustinger, 1991; Diamant, 1979; Sichon, 1988; González, 2009).

La compañía "Botwin" fue creada en diciembre de 1937, en el marco del batallón Palafox de la $13^{\text {a }}$ Brigada polaca Dumbrowski. Rápidamente se convertiría en un símbolo de la participación judía en la Guerra Civil española, aunque la gran mayoría de voluntarios judíos no lucharían en sus filas (Zaagsma, 2011, 393-397; Rothenberg, 1980, 14-19). Designada oficialmente como una compañía judía, llegó a incluir de hecho también varios voluntarios no-judíos, sobre todo polacos, alemanes y españoles, e incluso a dos árabes, uno de ellos un panadero de Palestina que hablaba ídish. La "Botwin" publicaba un boletín en el frente, llamado como la compañía, que glorificaba el apoyo judío al esfuerzo bélico republicano y a la lucha antifascista (Núñez Díaz-Balart, 2006). Una idea inicial de llamar a la compañía "Bar Kokhba" (el líder de la rebelión judía contra el imperio romano en el siglo II) fue rechazada en favor del adoptado en homenaje al activista sentenciado a muerte tras disparar a un oficial de policía que se había infiltrado en las filas del Partido Comunista en Lwow (Leópolis). Botwin se transformó en un símbolo de sacrificio personal revolucionario para mucho de los afiliados al partido, judíos y no-judíos por igual (Medem, 1937).

Martin Sugarman ha ofrecido una serie de estadísticas que nos dan una idea aproximada acerca de la participación judía en la defensa de la República (Sugarman, 2014). De los 5.000 voluntarios polacos, 2,250, el 45\%, eran judíos. En aquel entonces, los judíos representaban tan solo el 10\% de la población polaca. En el caso de los EE.UU., Sugarman estima el número de voluntarios judíos en 1.250, es decir el 38\% del total de estadounidenses alistados en las Brigadas Internacionales, en un tiempo en el que los judíos representaban solamente el 4\% de la población del país. El historiador Robert Rosenstone por su parte estima que 30\% de los voluntarios norteamericanos eran judíos (Rosenstone, 1969, 368-69). Los 1.043 voluntarios franceses-judíos constituyeron el 15\% de todos los voluntarios franceses, componiendo los judíos o,5\% de la población de Francia. Entre 200 y 400 
judíos partieron de Gran Bretaña hacia la península ibérica, es decir un 11-22\% de todos los voluntarios británicos, mientras que los judíos también en este caso representaban solamente un $0,5 \%$ de la población de este país. La proporción de judíos entre los voluntarios de cada país fue, incluyendo la Argentina, muy superior a su grado de representación dentro del total de la población de esos países.

La postura de muchos de estos voluntarios era internacionalista, por lo que les era ajena la idea de resaltar su identidad judía. Pese a ello, en la práctica, tal como se refleja en las cartas que enviaron desde las trincheras o en sus memorias, yo sostengo que el componente judío de su identidad sí tuvo un papel crucial en sus decisiones de partir hacia España. ${ }^{4}$ Esta destacada presencia de judíos en las Brigadas Internacionales contribuyó al fortalecimiento de estereotipos antisemitas entre los nacionalistas españoles, que a menudo equiparaban a judíos con bolcheviques, como puede verse en las publicaciones de la Falange en aquellos años (Álvarez Chillida, 2002; Rohr, 2008). Pese a ello, aunque es posible encontrar una voluminosa bibliografía sobre los voluntarios europeos judíos o estadounidenses judíos, hay una conspicua ausencia en la historiografía relativa a los argentinos-judíos en la Guerra Civil española.

\section{La polarización de la sociedad argentina en torno a la Guerra Civil}

La Guerra Civil en España dividió a la sociedad argentina en líneas similares al conflicto original (Bocanegra Barbecho, 2009; Falcoff, 1982; Montenegro, 2002; Quijada, 1991). Mientras que en Europa Occidental y los Estados Unidos se veía la contienda como un enfrentamiento entre fascismo y democracia, los latinoamericanos la percibían en términos más complejos y la observaban utilizando el prisma de sus propios problemas internos que, en muchos casos, se asemejaban a los de España en la década de 1930. Las dificultades que suponía la modernización y los obstáculos para lograrla; la necesidad de reconciliar, tanto en lo social como en lo político, constituciones del siglo XIX con formas de vida modernas; los problemas vinculados a la reforma agraria; la intervención de las fuerzas armadas en la vida política; la relación entre Iglesia y Estado. Todos estos eran temas que estaban sobre el tapete en cada uno de los países hispanohablantes.

4 Rueda Laffond (2019) habla de la identidad híbrida de los judíos comunistas en las Brigadas Internacionales. 
En general, hubo una diferencia significativa en las actitudes adoptadas por los gobiernos y las elites gobernantes de América Latina por un lado, y el público en general por el otro. Mientras que los primeros mostraron en mayor o menor medida cierto apoyo a quienes se rebelaron contra el gobierno legítimo de España, la mayor parte de la opinión pública respaldaba a la asediada autoridad de la República. Cabe señalar que cuando estalló la Guerra Civil, en julio de 1936, la mayor parte de las repúblicas iberoamericanas se encontraban regidas por militares y la mayoría de los regímenes podrían definirse como autoritarios y representando a los intereses de una pequeña oligarquía. Tanto los militares como las elites tradicionales temían a los procesos de democratización y radicalización social que amenazaban sus propias posiciones y privilegios. No sorprende, entonces, que la mayoría de ellos siguiera de cerca y con ansiedad lo que ocurría en Madrid desde 1931, ni que manifestaran simpatías por quienes se alzaron contra la República “bolchevique y masónica” (Quijada, 1991).

En la Argentina, quizás en mayor medida que en otros lugares de América Latina, la opinión pública se inclinaba a favor de los Republicanos, aunque hubo algunos elementos influyentes en la sociedad que simpatizaban con los rebeldes. Esto pudo notarse durante las presidencias de Agustín P. Justo (1932-1938) y Roberto M. Ortiz (1938-1940), que apoyaban en mayor o menor grado la rebelión nacionalista liderada por el general Francisco Franco, en la creencia de que era el mejor servicio que podían dar también a los "intereses nacionales" de la Argentina. No obstante, la mayor parte de la opinión pública no estaba convencida de la "necesidad" de tal apoyo y continuó expresando cierto desagrado por la cooperación con Franco, incluso en los años que siguieron a la finalización de la contienda fratricida (Romero, 2011; Rein, 2016).

La postura oficial del gobierno argentino fue de neutralidad, siguiendo los ejemplos de Gran Bretaña, Francia y los Estados Unidos, con el fin de evitar aireadas protestas públicas; aunque el régimen no tenía por qué temer en cuanto al daño electoral de su actitud, ya que las elecciones por aquel entonces se llevaban a cabo mediante fraudes y falsificaciones. En la práctica, no obstante, adoptó varias medidas que dañaron los intereses del gobierno de la República española.

El canciller Carlos Saavedra Lamas estaba involucrado en intentos de mediación por resolver el conflicto en forma que promovía la posición internacional de los rebeldes. En el mismo sentido actuó el embajador argentino en Madrid, Daniel García Mansilla, durante las primeras semanas de la guerra. En su carácter del presidente de la Asamblea General de la Liga de Naciones en Ginebra, Saavedra Lamas abortó los intentos 
de tratar la violación del Acuerdo de No Intervención por parte de Italia, Alemania y Portugal, los aliados de los nacionalistas rebeldes (Figallo, 2016).

En el frente doméstico, las autoridades argentinas obstruían las actividades de organizaciones pro-republicanas (Falcoff, 1982; Montenegro, 2002). En septiembre de 1936 se prohibieron todos los mítines políticos y las manifestaciones a la intemperie. Las reuniones se aprobaban solo en caso de ser en interiores y con autorización policial. En noviembre, el Senado sancionó una ley que prohibía el comunismo y fue formulada de manera tal que podía interpretarse asimismo para impedir actividades que apoyaran a la República Española. Un año más tarde se restringía aún más la libertad de asamblea. En varias ocasiones fueron dispersadas manifestaciones que expresaban su solidaridad con el bando republicano, incluso en ocasiones en que habían obtenido todos los permisos exigidos por las autoridades necesarias. Se detuvo a mujeres que hacían colectas en las calles porteñas con diversos pretextos. También se obstaculizó de varias formas la distribución de publicaciones pro-republicanas. En cambio, los simpatizantes con el bando franquista no tenían impedimentos, al menos hasta la presidencia de Ortiz.

La mayor parte de las fuerzas políticas opositoras simpatizaban con la República, incluyendo la Unión Cívica Radical (UCR), representante de la clase media; el Partido Demócrata Progresista (PDP); el Partido Socialista Argentino (PSA); el Partido Socialista Obrero (PSO) y los sindicalistas de la Confederación General del Trabajo (CGT). No obstante, fue el Partido Comunista Argentino (PCA) quien tuvo un papel crucial en la movilización de apoyo, fondos y voluntarios para la causa republicana (Piemonte, 2016). Hay que tener en cuenta que tras el golpe militar de 1930, el PCA fue declarado ilegal. Tenía no más de 5.000 afiliados, muchos de ellos eran inmigrantes. Sin embargo, contaba con un número creciente de simpatizantes y adherentes en organizaciones vinculadas al partido. Con el giro de la Comintern en 1935 y la promoción de los frentes populares, pudo acercarse al socialismo, a los radicales y al centro liberal. Los comunistas encabezaron el movimiento de solidaridad con la República española y esta actividad se transformó en el eje central de sus actividades. En este sentido, los comités de ayuda a España sirvieron a la vez como un escudo bajo el cual podían refugiarse y una plataforma para ganar apoyo de las masas en la arena política local, el sindicalismo y el campo cultural.

Cientos de voluntarios, la mayor parte de ellos comunistas, salieron de la Argentina para combatir en España, a pesar de que la embajada de la República en Buenos Aires no fue parte activa en la campaña de 
reclutamiento y de que el gobierno les causó dificultades para ir (Castells, 1974; Baumman, 1997). Victorio Codovilla, líder del PCA y estalinista intransigente, incondicionalmente leal a Moscú, fue el enviado del Comintern en España en la década de 1930. Trabajó para los republicanos utilizando el alias 'Medina', e intentó promover allí la cooperación entre comunistas y socialistas locales. Durante el primer año de la Guerra Civil, Codovilla fue de hecho el líder del Partido Comunista Español (PCE). Dolores Ibárruri (la Pasionaria) lo elogió en sus memorias por su aporte al movimiento. Otra figura destacada del PCA, Juan José Real, combatió con las Brigadas Internacionales desde fines de 1936 hasta la rendición final de la República, que fue cuando regresó a su país, donde se desempeñó como secretario de organización del Comité Central del partido (Alba, 1983; Gilbert, 2009; Jeifets, 2004; Codovilla, 1942).

\section{Argentinos-judíos y el conflicto español}

Mientras que muchos argentinos simpatizaban con la República como parte de su lucha por una sociedad democrática, pluralista y socialmente justa en su propio país, los argentinos-judíos tenían razones adicionales para justificar su apoyo a la causa. Por un lado, estaban preocupados por el destino de sus parientes que habían quedado en Europa y lo que podría ocurrirles en caso de surgir otro régimen tiránico con la ayuda de los nazis y fascistas. Simultáneamente buscaban proteger su espacio en la Argentina, en tiempos de creciente influencia de los nacionalistas de derecha en círculos políticos, militares e intelectuales (McGee Deutsch, 2005; Finchelstein, 2012, 2016), tal como lo expresó elegantemente Samuel Glusberg, firmando con su seudónimo Enrique Espinoza, en un artículo titulado "Por qué los judíos deben ayudar al pueblo español”, publicado en el mensuario Judaica, que dirigía Salomón Resnick, en julio de 1937:

Ante todo: por una razón de justicia, que en eso consiste ser hombre y ser judío. Después, en defensa propia, porque el enemigo número uno del judío es el mismo del pueblo español. Finalmente, porque en la convivencia histórica durante siglos, solo la segunda república se apresuró a reconocer en forma oficial a los judíos.

Contra esta República se levantaron precisamente, a los pocos meses de proclamada, los generales facciosos del rey, con Sanjurjo a la cabeza, para reducir al pueblo español a la misma condición que sus muy ilustrísimos antepasados habían logrado reducir al judío... Ahora bien, ¿puede el judío que, como el criollo, ha sentido por así decirlo en carne propia, los extremos a los que es capaz de recurrir la 
casta feudal y militarista en defensa de sus privilegios más odiosos, adoptar una actitud contemplativa frente a la guerra totalitaria que los últimos generales borbónicos están llevando hoy a sangre y fuego contra el pueblo español, en complicidad con las huestes negras del Duce y del Führer? De ninguna manera. El judío, para ser consecuente consigo mismo, debe de ponerse cuanto antes de parte del pueblo español en ese definitivo juego de vida o muerte y echar el resto, según la profunda expresión de nuestro idioma, en su favor. De lo contrario, tarde y temprano le ocurriría lo que al judío alemán que no supo sumarse a tiempo a la campaña contra Hitler (Espinoza, 1937).

La Comisión Israelita de Ayuda al Pueblo Español (CIAPE) tenía 15 sucursales a lo largo y ancho de la Argentina, que distribuyeron los panfletos que publicaba en ídish convocando a los judíos a apoyar a la sitiada República Española y lograron recolectar no menos que 100.000 pesos en la comunidad (McGee Deutsch, 2012b, 181-182; González et al, 2008, 47). La CIAPE explicaba que solidaridad, democracia e idealismo eran los móviles del apoyo judío a la República y caracterizaba a los rebeldes nacionalistas como antisemitas. Las publicaciones en ídish del PCA tenían una extensa cobertura del conflicto ibérico, al que dedicaron más espacio que a expresiones antisemitas en Europa o la Argentina (Schenkolewski-Kroll, 1999). Desde sus páginas llamaban a sus lectores a donar dinero, alimentos y medicinas, así como a enrolarse para combatir en España. Jóvenes judíos, varones y mujeres, juntaron hojas de estaño, ropas y contribuciones materiales para la defensa de la República. A los agricultores judíos en las colonias se pidió donar parte de sus cosechas al pueblo español.

Destacados comunistas argentinos-judíos tuvieron un papel importante en el Comité de Ayuda a la España Republicana (como fue el caso de Iosif Grigulevich, hasta que fue arrestado por la policía argentina y posteriormente enviado a Madrid, tras una mediación diplomática) o en Socorro Rojo (por ejemplo: Elsa "Lola” Rabinovich). Esto no debe sorprendernos. En 1936 el 50\% de los integrantes de las comisiones del PCA, con puestos de responsabilidad eran argentinos-judíos (Boragina y Sommaro, 2016, 166).

La solidaridad con la República y el apoyo a la causa no se limitó a los judíos de Buenos Aires o a los judíos askenazíes. Alberto Cohen, nacido en San Miguel de Tucumán a comienzos de 1927, hijo de padres nacidos en Esmirna, recuerda la atmósfera en su ciudad natal a fines de la década de 1930: "Claro, nosotros seguíamos sintiéndonos Republicanos a pesar de todo, y por eso, como éramos consecuentes con nuestras idea,... nos afiliamos a la Juventud del Partido Socialista" (Cohen de Chervonagura, 2010, 245). 
Numerosos judíos que hasta entonces no habían participado en política, se afiliaron a diversos comités de ayuda. La socialista Rosa Scheiner creía que la Argentina se dirigía a un enfrentamiento intestino similar al español. Como muchos otros, temía que una victoria rebelde iba a fortalecer a los nacionalistas argentinos. La comunista Fanny Edelman compartía militancia con su marido Bernardo, lo que llevó a ambos a participar en la Guerra Civil española. Fue un enfrentamiento transnacional, librado a ambos lados del Atlántico e intensificado por el movimiento de gente e ideas hacia una y otra orilla.

Otra argentina-judía que se identificó con la causa republicana fue Berta Singerman. Comenzó su carrera en el teatro en ídish y adquirió fama nacional e internacional como recitadora. En el apogeo de su carrera declamó ante un público de 70.000 personas en Córdoba. En su autobiografía, Mis dos vidas, da testimonio de su amor por la poesía española y su simpatía por el proyecto republicano de justicia social y de libertad (Singerman, 1981). Berta actuó junto con su hermana Paulina en actos a favor de la República y se negó a visitar España después de que se consolidó allí el régimen nacionalista.

Sandra McGee Deutsch enfatizó la forma en que "la Guerra Civil española convirtió en militantes a numerosas jóvenes askenazíes... [y] las indujo a la política de tendencias izquierdistas" (McGee Deutsch, 2012b, 182). Efectivamente, mujeres judías ayudaron a la República mediante la CIAPE u otras asociaciones, en el marco de la Federación de Organizaciones de Ayuda a la República Española (FOARE) cuyo secretario general era el argentino-judío Abraham Schuckman. Este último viajó también a España y se transformó en uno de los combatientes argentinos en la península. Las expresiones de solidaridad con la República por parte de mujeres argentinas-judías se notaban tanto en la Capital Federal, como en el conurbano y el interior. Muchachas judías en Quilmes, Once y Villa Crespo, o en Villa Domínguez y Moisés Ville, recolectaron fondos y organizaron reuniones sociales de diversos tipos para ayudar al pueblo español.

A menudo la policía reprimió manifestaciones favorables al gobierno de izquierda en España. Simpatizantes pro republicanos, judíos y no judíos por igual, fueron víctimas de una política que consideraba tales actividades como una amenaza al orden social establecido en la Argentina. Al fin y al cabo, para muchos políticos, oficiales estatales y militares, policías y periodistas, ser judío, comunista y pro republicanos era prácticamente lo mismo. En 1939 se prohibió un festival de solidaridad con la República que iba a celebrar en Moisés Ville. También se castigó al conjunto teatral 
judío anarquista de la familia chaqueña Bursuk, que donaba parte de sus ingresos a fondos para refugiados españoles (McGee Deutsch, 2012b, 183).

\section{Médicos, traductores y comisarios políticos: los voluntarios argentinos-judíos}

La movilización de apoyo material para la República Española era notable y la Argentina se encontraba entre los primeros países del mundo en este respecto, en proporción a su población. En cuanto al número absoluto de voluntarios que combatieron en España, fue el segundo en América Latina, después de Cuba y antes que México. Mientras que algunos autores (Romero, 2011; Figallo, 2016) tienden a minimizar el número de argentinos engrosados en las Brigadas Internacionales y evaluarlo entre 200 y 500, algunas organizaciones de izquierda como el ICUF hablan de hasta mil voluntarios. Investigaciones recientes han establecido que el número de voluntarios argentinos oscila entre los 500 y 600 . El menor de los voluntarios tenía 17 años y el mayor 55, pero la mayoría estaba en sus veinte, sin experiencia militar previa.

No queda claro cuántos de ellos eran de origen judío. La lista más completa de voluntarios incluye 540 nombres de individuos que lucharon en las filas del Ejército de la República, las Brigadas Internacionales o las Milicias (González, et al., 2008, 175-201). Ninguno de estos voluntarios es identificado por los compiladores de la lista como judío, pero puestos en orden alfabético, los primeros son Benzión Abramson y sus hijas, Adelina y Paulina, y hacia el final se encuentran Zalman Izraelevich Yaselman e Hishel Zukerman. Cuando se pasa revista a los apellidos, resulta evidente que alrededor de $15 \%$ eran de origen judío. Obviamente, había también judíos en la Argentina, como en todas partes, que adoptaron apellidos que no son típicamente judíos. Según una importante autoridad en demografía judía, el número de judíos en Argentina en 1930 era 191.400 en una población total de 12 millones, o sea el 1,6\% (DellaPergola, 1987). Es interesante que tal desproporción de judíos entre los voluntarios argentinos no recibió suficiente atención de investigadores.

Muchos de los voluntarios judíos eran argentinos de primera generación nacidos principalmente en Europa Oriental (como Benzión Abramson, Baumkoler, Davidoff, Elguer, Fijtman, Goldstraj, Lipovetzky, Prince, Radowitzky, Sosnowski, Steinmetz o Yaselman). La provincia de Santa Fe (Feldman de Etchebehere, Grunfeld y su compañera Ana Piacenza, Maguid, Segal) y la ciudad de Córdoba (Bermann, Corach, De Galer, 
Edelman, Mochkofsky, Ostrowski, Serebrinsky) estuvieron claramente sobrerrepresentadas entre los voluntarios argentinos judíos. Gobernada por el radicalismo, en la provincia de Córdoba las agrupaciones de ayuda a los republicanos españoles funcionaban legalmente, sin obstáculos ni restricciones para el desarrollo de sus actividades ni persecuciones por parte de la policía.

Carlos Corach, el Ministro del Interior en los años noventa, asigna a su tío Luis un lugar importante para explicar su pasión por la política: “A los antecedentes políticos debo agregar a mi tío Luis Corach, que peleó en la Guerra Civil española. Había sido reclutado en Córdoba y, siendo estudiante de medicina, se enroló en las Brigadas Internacionales y terminó la guerra en Barcelona; a través de sus vinculaciones socialistas mi padre consiguió trasladarlo a París, de donde regresa a la Argentina..... 5

Efectivamente, la misma afirmación acerca de una notable representación puede hacerse para determinadas profesiones, como médicos y enfermeras (como Bermann, Corach, Feldman de Etchebehere, Fijtman, Goldstraj, Iaffa, Jungman, Matkovich, Ostrowsky, Poliak, Serebrinsky, Sukarte, Topolevsky y Marie Langer) (Langer, 1989), y traductores (como las hermanas Abramson, Baumkoler, Joucovsky, Rosen, Steinmetz, Yaselman) en la Guerra Civil española. Esto refleja que el PCA logró movilizar apoyo entre estudiantes y docentes judíos en las universidades de Buenos Aires y Córdoba. En lo que se refiere a traductores, muchos argentinos judíos eran bi- o incluso trilingües. En la España Republicana, con numerosos asesores rusos y miembros de las Brigadas Internacionales provenientes de Europa Oriental, el poder comunicarse en español y también en ruso/ polaco/alemán/ídish era algo valorado.

Salomón Elguer (alias Carlos González Díaz), nacido en Buenos Aires en 1906, fue carpintero y militante de la Fede desde 1924. Hablaba cinco idiomas y llegó a España en marzo de 1937, enviado por el PCA. Fue uno de los traductores en las Brigadas Internacionales, pero también se desempeñó como comisario político del Servicio Médico para controlar la "salud ideológica” de los voluntarios.

Gregorio Bermann, uno de los pioneros del psicoanálisis en la Argentina, volvió de inmediato a participar en actividades prorepublicanas en la provincia de Córdoba, una vez que estalló la guerra en España (Fitó; Bermman 1937, 1971). Nacido en 1896, Gregorio fue el menor de ocho hermanos de

5 Corach $(2011,18)$ y entrevista del autor con Carlos Corach, Buenos Aires, octubre de 2013. 
una familia judía que había emigrado de Polonia para evitar el servicio militar de sus hermanos mayores en la Rusia de aquellos años. Como joven estudiante fue presidente de la Federación Universitaria de Buenos Aires y participó activamente en la dirigencia de la Reforma Universitaria de 1918. Luego ejerció la cátedra de Medicina Legal de la Universidad Nacional de Córdoba, hasta que las autoridades surgidas del golpe de 1930 lo expulsaron por razones políticas. En 1932 fue candidato a gobernador de la provincia de Córdoba por el socialismo y la Alianza Civil. Para mediados de los años treinta ya se alejó del socialismo y se acercaba al Partido Comunista, sin llegar nunca a afiliarse.

En poco tiempo entendió que podía ser más útil a la causa estando en la península ibérica y ofreció sus servicios como médico psiquiatra al gobierno republicano español. Poco más de un año duró su experiencia española y publicó sus impresiones de la misma en su libro Dialéctica del fascismo, publicado en Madrid en 1937. A fines de 1938 ya estaba de regreso en la Argentina. Durante décadas seguía manteniendo vivo el recuerdo de España.

Obviamente, no todos los voluntarios argentinos eran comunistas. Entre los anarquistas se destacaba Ramón Belanguer García, que luchó en la columna de Buenaventura Durruti, pero hubo también socialistas, republicanos sin partido y hasta un aristócrata, Carlos Kern Alemán, primo hermano de los economistas Juan y Roberto Alemán. Lo mismo podemos afirmar acerca de los argentinos-judíos. Varios de los voluntarios argentinos de origen judío eran anarquistas. El más conocido entre ellos fue José Grunfeld, nacido en Moisés Ville (Grunfeld, 200o). Grunfeld, su compañera Anita Piacenza y Jacobo Prince formaron parte del grupo libertario Ideas, junto con el escritor Jacobo Maguid (conocido por sus seudónimos Jacinto Cimazo o Macizo). Los cuatro llegaron a España, donde Maguid asumió la dirección del periódico Tierra y Libertad que su compañero Diego Abad de Santillán dejó para desempeñar otras tareas.

Grunfeld desembarcó en Barcelona llevando un cargamento de 40.000 inyecciones de antipiógeno, que se utilizaba contra las infecciones y que fueron elaboradas por estudiantes de la Facultad de Química. Desarrolló importantes tareas de dirección y organización desde el secretariado local de la FAI de Barcelona, y como consejero en la Comisión de Guerra de la CNT-FAI. Jacobo Prince, entre otras actividades, integró la jefatura de redacción del periódico Solidaridad Obrera (Cimazo, 1984). Otros argentinos-judíos anarquistas incluyeron a María Claramunt, nacida en Argentina y dirigente de Mujeres Libres, y su hermana Minerva, así como el periodista platense, David Kraiselburd. 
$\mathrm{Al}$ analizar la participación judía desde la óptica de los estudios de género, se nota claramente que la presencia de mujeres judías fue sobresaliente entre las voluntarias argentinas (Boragina, 2010). Sara Segal dejó la ya por entonces mitológica colonia agrícola Moisés Ville camino a España, junto con su pareja, el ingeniero Samuel Joukovsky (Joukovsky, 1998). Lilia Bondareva, nacida en Viena, era filóloga y militante de la Fede en Argentina. Se casó con el dirigente del PCA Luis Víctor Sommi. En 1937 fue enviada como traductora de la misión soviética en España y regresó a Buenos Aires al año siguiente.

Raquel Levenson, casada con el secretario de organización de la Federación Juvenil Comunista, Juan José Real, fue por varios años responsable del frente de educación de la Federación. Con solo veintiún años organizó la solidaridad con España en Córdoba. Según el testimonio de su hermano Gregorio:

Nuestra actividad era de agitación y, desafiando el terror de Justo, organizábamos mítines callejeros, en los que mi hermana Raquel era la oradora infaltable, subida a un cajón, custodiada por una guardia de autodefensa integrada por rusos y polacos. Improvisábamos nuestros actos a la salida de las fábricas o en las esquinas concurridas. Antes de que llegara la policía, ya habíamos desaparecido. Aunque siempre fue así, más de una vez nos sorprendió a mitad del acto y la 'guardia', con una fidelidad a toda prueba, contenía a los esbirros mientras nosotros huíamos como podíamos (Levenson, 2000).

Poco después Raquel se fue con su marido a España y su embarazo no fue obstáculo para que continuara trabajando para el partido (Comisión de Redacción de PCA, 1972). De España pasó a la Unión Soviética, donde quedó atrapada por la Segunda Guerra Mundial. Regresó a la Argentina a finales de los años cuarenta.

A Fanny Edelman le cupo un papel de liderazgo en el Comité Argentino de Mujeres Pro Huérfanos Españoles. En sus memorias, Banderas, pasiones, camaradas, cuenta que en España se dedicó a trabajar para el Socorro Rojo Internacional, organización auspiciada por los comunistas (Edelman, 1996). A su regreso a la Argentina, Fanny fue promovida a ser miembro del Comité Central del Partido y a responsable femenino del CC (Pieper Mooney, 2013). Las hermanas Abramson, Paulina y Adelina, nacidas en Buenos Aires en el seno de una familia de inmigrantes judíos de Rusia, regresaron con sus padres a Moscú en 1932 y de allí fueron a España pocos meses después del comienzo de la Guerra Civil (Abramson, 1994). Los tres trabajaron como traductores e intérpretes de los asesores 
rusos. Berta Baumkoler ya había llegado a España en 1934 para encontrarse con su marido Mendel. En su libro La lucha es vida cuenta que no se limitó a enseñar en escuelas para soldados revolucionarios o a organizar comedores, sino que también cumplió guardias en cuarteles comunistas (Baumkoler, 2000). Al final de la guerra fue tomada presa y enviada a la cárcel de Ventas. Logró salir de España en 1941.

La legendaria figura de Micaela "Mika” Feldman, sin embargo, ha atraído mayor atención en los últimos años, por ser la única mujer con mando de tropa en el Ejército Republicano. Nacida en Moisés Ville, Provincia de Santa Fe, a comienzos del siglo XX. Sus padres, rusos judíos, habían llegado a la Argentina huyendo de los pogroms. Por entonces, su padre enseña ídish en la colonia patrocinada por el Barón Hirsh. Ya a los 14 años, mientras cursaba estudios en el Colegio Nacional de Rosario, empezó su militancia política en un grupo anarquista. Feldman se convirtió en dentista y tuvo una larga trayectoria de actividad revolucionaria. El año 1919 y los episodios antisemitas de la Semana Trágica fueron decisivos para su carrera revolucionaria y la de su futuro esposo:

Llega así el año 1919 con su semana trágica del mes de enero. La huelga de Vasena paraliza la metalurgia. La revolución rusa exaspera el antisemitismo de los reaccionarios. Por entonces todavía se llamaba rusos a los judíos. Entre Paso y Junín, de Corrientes a Tucumán, vive 'la rusada'. La gentuza responsable de los disturbios obreros, causante de la lucha que llevan los obreros de Vasena en una huelga que por su magnitud y firmeza hace temblar a la burguesía y desata el frenesí argentinista de la Liga Patriótica de Carlés. Detrás de los niños bien que forman la tropa de la Liga Patriótica, entra al barrio de los rusos el escuadrón de seguridad. Para escarmiento de esos bolcheviques subversivos que venden arenques salados y pepinos, son sastres o carpinteros, los jinetes del escuadrón arrastran entre sus caballos, atados por la barba a los viejos, uncidos a las monturas de los jóvenes. Las calles se manchan de sangre. Teníamos entonces de presidente a Hipólito Irigoyen. mediante una huelga que, por su dimensión y firmeza, hacía temblar a la burguesía (Tarcus, 2000).

Tras un breve período en círculos anarquistas en Rosario, se sumó al ala izquierda del PCA en 1923, en parte por su relación con Hipólito Etchebehere, un estudiante de ingeniería que militaba en el Partido. Participó en el Comité Comunista Femenino bregando por leyes laborales para proteger a las mujeres trabajadoras, aunque no pasó mucho tiempo para que Feldman y Etchebehere fueran expulsados por su radicalización e "inclinaciones trotskistas". Fue una de las fundadoras del Partido 
Comunista Obrero, organización que también terminó dejando para recorrer la Patagonia con un consultorio odontológico ambulante.

En su autobiografía Mi Guerra de España, cuenta cómo a principios de la década de 1930 llegó con su pareja Hipólito primero a Alemania y Francia y luego a la península. Una vez allí se sumaron al Partido Obrero de Unificación Marxista (POUM), de orientación trotzkista. Cobró fama cuando al caer Etchebehere el 16 de agosto, en las afueras de Atieza, ella asumió el mando del regimiento, elegida por los propios milicianos, y obtuvo el rango de capitán de la segunda compañía del POUM. Finalmente, después de que las tropas del POUM fueron abatidas, Mika quedó detenida y acusada por los comunistas de ser contraria a la República. Una vez tomada Madrid por los franquistas, en marzo de 1939, Mika sigue la lucha desde la clandestinidad. Sin embargo, una patrulla franquista la detiene. Con su pasaporte francés encuentra asilo en el Liceo Francés durante varios meses, hasta que logra llegar a París.

La mayor parte de los artículos y sitios web dedicados a Feldman y a su carrera revolucionaria omiten su condición de judía. A lo sumo mencionan que sus padres eran inmigrantes de Europa Oriental y que nació en Moisés Ville (Feldman, 1987; Osorio, 2012). Feldman mantuvo su postura antifranquista muchos años después de la derrota de la República. Efectivamente, en el período posterior a 1939 fueron muchos los argentinos, incluyendo argentinos-judíos, que enviaron dinero a refugiados españoles y protestaron contra las políticas brutales del General Franco (McGee Deutsch, 2012a).

Entre los voluntarios argentinos judíos, los más famosos fueron quizá Simón Radowitzky y Benigno Boris Mochkofsky. Nacido en el seno de una familia judía de trabajadores en Ucrania, Radowitzky estuvo muy involucrado en la política revolucionaria desde temprana edad. Llegó a Argentina en 1908, y pronto se unió a un grupo de anarquistas exiliados rusos. Después de la brutal represión de la demostración del 1 de Mayo de 1909, Radowitzky decidió eliminar al jefe de policia Ramón Falcón, de infame reputación reaccionaria y antisemita; asesinato por el que fue sentenciado a cadena perpetua. En 1930, como resultado de una larga campaña para asegurar su liberación, fue expulsado de Argentina. Cuando la Guerra Civil española estalló, él partió hacia la península ibérica. En Aragón se reunió con la división anarquista y más adelante, trabajó en Barcelona para la división cultural del sindicato anárquico CNT. Con la victoria de Franco, tuvo que huir a Francia, desde donde partió a México (Marti, 2010).

Mochkofsky, mejor conocido como Comandante Ortiz o Miguel Ortiz Mora, puede servir como ejemplo de numerosos comunistas argentinos-judíos 
comprometidos con la lucha internacional para establecer una sociedad más justa (Mochkofsky, 2006). A comienzos de la década de 1930, tras haber sufrido torturas en el penal de Ushuaia durante el breve gobierno de Uriburu, fue enviado por el PCA a Bolivia, donde fue nuevamente arrestado por participar en actividades revolucionarias. Liberado en 1933 gracias a la intervención de dos oficiales españoles, llegó a la península y allí se encontró con Victorio Codovilla, el líder del PCA que tuvo que dejar su país en 1930 y fue el delegado de la Internacional Comunista en España durante los años treinta. Mochkofsky trabajó para el Comité de Ayuda a los Prisioneros Políticos tras la fallida rebelión de octubre de 1934 en Asturias y en vísperas de la Guerra Civil se sumó a las Milicias Antifascistas Obreras y Campesinas. Durante la contienda llegó a comandar la XXIV Brigada del Ejército Republicano y participó en la defensa de Madrid y otras batallas de importancia. En sus memorias lo elogian tanto el general Enrique Líster como La Pasionaria. Tras la caída de Cataluña, partió hacia Francia y allí fue arrestado con muchos otros exiliados republicanos. Recién en 1940 regresó a la Argentina.

\section{Conclusiones}

En un informe del matutino israelí Haaretz sobre las elecciones para el gobierno de la Ciudad Autónoma de Buenos Aires (20/6/2011), el diario destacó la biografía de uno de los candidatos, Jorge Telerman y en particular que su abuelo paterno, Froike, fue un obrero de la construcción y militante socialista que, junto con su esposa, participó en una misión de apoyo para las Brigadas Internacionales durante la Guerra Civil. En una entrevista que me concedió, Telerman contó que al terminar la Guerra Civil española su abuela solía viajar al Uruguay, vestida como un hombre y llevando una documentación falsificada para ayudar a exiliados españoles a entrar en la Argentina. Después de entregar esta documentación, volvía a Buenos Aires con su propia documentación como mujer. ${ }^{6}$

Bajo la sombra de una política de prescindencia del gobierno nacional, el apoyo a la República durante la lucha fratricida atrajo en la Argentina por aquellos años mayor participación que cualquier otro movimiento político, con la participación de grupos sindicales, partidos políticos, gran variedad de asociaciones de la sociedad civil, los medios de comunicación en su mayoría y un número importante de intelectuales. Este movimiento de solidaridad se expresó en colectas, protestas, actos callejeros, reuniones y

6 Entrevista del autor con Jorge Telerman, Buenos Aires, septiembre de 2013. 
festividades de todo tipo. En parte, esto se debió a las raíces españolas de muchos argentinos, pero también a la sensación de amplios sectores de que la República confrontaba desafíos similares a los de la sociedad argentina, que a la sazón veía la creciente influencia de grupos nacionalistas, fundamentalmente anticomunistas y antisemitas, de la Iglesia católica como institución y de los círculos militares.

Precisamente por este auge nacionalista, Argentina no fue un país de acogida para el exilio republicano (o para judíos huyendo del nazismo y el Holocausto) y optó por una política de restrictiva inmigratoria. A partir de 1939 empezaron a llegar exiliados españoles, pero no en contingentes numerosos, sino en un goteo continuado. De todos modos, este movimiento de solidaridad durante la Guerra Civil española definió los campos, identidades y tradiciones políticas en la Argentina, más allá de los años treinta.

La presencia judía entre los argentinos que apoyaron al bando republicano fue notoria. Muchos de los judíos participaban en movimientos sindicales y de izquierda del país desde antes y en los años treinta consideraron vital enfrentar y resistir todo aquello que se pareciera al fascismo, dentro y fuera de la Argentina. No debe sorprender, por consiguiente, que se sumaran a una variedad de manifestaciones de solidaridad con la República Española, luchando por su supervivencia contra sus enemigos nacionalistas que contaban con el apoyo de la Alemania hitleriana y la Italia de Mussolini. Al combatir la causa fascista defendían sus espacios en Argentina y luchaban por mayor pluralismo, democracia y justicia social. Para ello, como para tantos otros judíos en muchos países, se trató de una lucha transnacional con metas nacionales (argentinas, francesas o estadounidenses).

Numerosos voluntarios en la Guerra Civil, independientemente de sus países de origen, eran de tendencias internacionalistas y no enfatizaban el componente judío en su identidad. No obstante, hay un punto que queda claro: la proporción de judíos entre los voluntarios de cada país fue, en la mayor parte de los casos, muy superior a su equivalente en la población general de ese país.

Incluso las biografías escritas por los familiares de destacados comunistas argentinos judíos, hubiesen luchado o no en España, eludieron la dimensión étnica quizás por no parecerles políticamente correcto resaltar ese aspecto. Tales son los casos de Tío Boris de Graciela Mochkofsky o El camarada Carlos de Alicia Dujovne Ortiz que narra la trayectoria de Carlos Dujovne que estudió en la Universidad Estatal de Moscú y durante la Guerra Civil fue secretario del comité regional del PCA en Córdoba (Argentina), donde intentó alistar voluntarios para ir a España a combatir (Dujovne Ortiz, 
2007). Diría que, lo hayan admitido o no, muchos de estos militantes de los años treinta manifestaban todo tipo de prácticas judías en sus vidas diarias, tales como el uso de palabras en ídish o su mero acento al hablar, sus hábitos alimenticios o de bebida e incluso su selección de amistades. O bien que sencillamente podían ser reconocidos como judíos, igualmente por otros congéneres o por no judíos, por sus rivales ideológicos o por sus camaradas.

En la actualidad tenemos una idea más aproximada a la realidad sobre la cantidad de voluntarios argentinos que combatieron en suelo español, los nombres de la mayor parte de ellos, lugar y fecha de nacimiento, profesión, organización política que los reclutó y la función que cumplieron durante la guerra. Sobre su etnicidad, en cambio, se sabe menos. Este artículo pretende despertar la conciencia de la necesidad de debatir la dimensión étnica de estos voluntarios. ${ }^{7}$ 


\section{Bibliografía}

》Abramson, P. y A. (1994). Mosaico roto. Madrid: Compañía Literaria.

»Alba, V. (1983). The Communist Party in Spain, New Brunswick, NJ: Transaction Books.

» Álvarez Chillida, G. (2002). El antisemitismo en España, Madrid: Marcial Pons.

»Avni, H. (2002). Argentina and the Jews, Tuscaloosa: University of Alabama Press.

» Baumkoler, B. (2000). La lucha es vida. Buenos Aires: Cuadernos Marxistas.

» Baumman, G. (1997). Los voluntarios latinoamericanos, San José, Costa Rica: Guayacán.

»Bermann, G. (1937). Dialéctica del fascismo y su psicopatología. Madrid: Psicoterapia.

»Bermann, G. (1971). Conciencia de nuestro tiempo. Buenos Aires: Editorial Hernández.

» Bocanegra Barbecho, L. (2009). “La República Argentina: el debate sobre la guerra civil y la inmigración." en Ay de los vencidos. El exilio y los países de acogida, ed. Abdón Mateos, 189-234. Madrid: Editorial Eneida.

"Boragina, J. E. (2010). "Mulleres arxentinas na Guerra civil española", Estudos Migratorios. Revista Galega de Análise das Migracións, Vol. III, No. 1, 117-137.

»Boragina, J. E. y Sommaro, E. R. (2016). Voluntarios judeo-argentinos en la Guerra Civil Española, Buenos Aires, Ediciones CCC.

»Castells, A. (1974). Las brigadas internacionales de la guerra de España, Esplugues de Llobregat, Barcelona: Ariel.

»Cimazo, J. (1984). Una voz anarquista en la Argentina. Vida y pensamiento de Jacobo Prince. Reconstruir, Buenos Aires.

»Cohen de Chervonagura, E. B. (2010). La Comunidad Judía de Tucumán, Hombres y Mujeres, Historias y Discursos 1910-2010, Tucumán: Universidad Nacional de Tucumán.

»Claret, J. (2016). Breve historia de las Brigadas Internacionales. Madrid: Catarata.

»Codovilla, V. (1942). José Díaz, ejemplo de dirigente obrero y popular de la época staliniana, Buenos Aires: Editorial Anteo.

»Comisión de Redacción de PCA. (1972). Raquel Levenson, ejemplo de una mujer revolucionaria. Buenos Aires: Frente Unido.

»Corach, C. (2011). 18.885 días de política, Buenos Aires: Sudamericana.

»De la Torre, F. R. (2006). Bibliografía de las Brigadas Internacionales y de la participación de extranjeros a favor de la República, 1936-1939. Albacete: Instituto de Estudios Albacetenses Don Juan Manuel de la Diputación de Albacete. 
»DellaPergola, S. (1987). "Demographic Trends of Latin American Jewry." En The Jewish Presence in Latin America, eds. Judith Laikin Elkin and Gilbert W. Merks. 85-133. Boston: Allen \& Unwin.

»Diamant, D. (1979). Combattants juifs dans L'Armée Republicaine Espagnole 1936-1939. Paris: Éditions Renouveau.

»Dujovne Ortiz, A. (2007). El Camarada Carlos. Itinerario de un enviado secreto, Buenos Aires: Aguilar.

»Edelman, F. (1996). Banderas, Pasiones, Camaradas. Buenos Aires: Dirple.

»Espinoza, E. (Samuel Glusberg). (1937). “Por qué los judíos deben ayudar al pueblo español”, Judaica 5/49 (julio):1.

»Falcoff, M. y Pike, F. B. (eds.). (1982). The Spanish Civil War, 1936-1939: American Hemispheric Perspectives. Lincoln: University of Nebraska.

» Feldman, M. (1987). Mi guerra de España. Madrid: Plaza y Janés.

»Figallo, B. J. (2016). “Con la república y contra la república. La Argentina y la guerra civil española”, Temas de Historia Argentina y Americana, No. 24: 41-81.

»Finchelstein, F. (2012). Fascismo transatlántico ideología, violencia y sacralidad en Argentina e Italia, 1919-1945, Buenos Aires: Fondo de Cultura Económica.

"Finchelstein, F. (2016). Orígenes ideológicos de la "Guerra sucia": fascismo, populismo y dictadura en la Argentina del siglo XX. Buenos Aires: Sudamericana.

» Fitó, José L. (s/f) "Gregorio Bermann: Reformista, pensador y Psiquiatra," http://www.polemos.com.ar/docs/temas/Temas6/1\%AA\%20parte\%20 Gregorio\%20Bermann.htm recuperado el 4 de diciembre de 2019.

»Gilbert, I. (2009). La FEDE: alistándose para la revolución, Buenos Aires: Sudamericana.

»González, I. (2009). Los judíos y la Guerra Civil Española. Madrid: Hebraica Ediciones.

»González, L. et al. (2008). Voluntarios de Argentina en la Guerra Civil Española. Buenos Aires: Ediciones del Centro Cultural de la Cooperación Floreal Gorini.

"Gould, C. C. (2007). "Transnational Solidarities", Journal of Social Philosophy, Vol. 38/1, pp. 148-164.

» Grunfeld, J. (2000). Memorias de un anarquista, Buenos Aires: Grupo Editor Latinoamericano.

» Hurtado, V. (2013). Atlas de la Guerra Civil española. Las Brigadas Internacionales. Barcelona: DAU.

» Jackson, M. W. (1986). "The Army of Strangers: The International Brigades in the Spanish Civil War", Australian Journal of Politics \& History 32/1: 105118.

» Jeifets, L. (2004). La Internacional Comunista y América Latina, 1919-1943: diccionario biográfico. Moscú: Instituto de Latinoamérica de la Academia de Ciencias. 
» Joukovsky, S. (1998). Uno de tantos. Un argentino en la guerra civil española, Buenos Aires: s/e.

"Kersffeld, D. (2012). Rusos y rojos: judios comunistas en tiempos de la Comintern. Buenos Aires: Capital Intelectual.

»Langer, M. (1989). From Vienna to Managua: Journey of a Psychoanalyst. London: Free Association Books.

"Levenson, G. (2000). De los bolcheviques a la gesta montonera. Buenos Aires: Colihue.

»Lustinger, A. (1991). Schalom Libertad! Juden in Spanischen Burgerkrieg. Köln: Kiepenheuer \& Witsch.

» Martí, A. (2010). Simón Radowitzky: del atentado a Falcón a la guerra civil española. Buenos Aires: De la Campana.

"McGee Deutsch, S. (2005). Las Derechas: La extrema derecha en la Argentina, el Brasil y Chile 1890-1939, Universidad Nacional de Quilmes, Bernal.

» McGee Deutsch, S. (2012a). "Argentine Women Against Fascism: The Junta de la Victoria, 1941-1947." Politics, Religion \& Ideology Vol. 13, No. 2 (June): 221-236.

" McGee Deutsch, S. (2012b). Crossing Borders, Claiming a Nation: A History of Argentine Jewish Women, 1880-1955. Durham: Duke University Press.

" Medem, G. (1937). Los judíos luchadores de la libertad: Un año de lucha en las Brigadas Internacionales. Madrid: Ediciones del Comisariado de las Brigadas Internacionales.

»Mochkofsky, G. (2006). Tío Boris. Un héroe olvidado de la Guerra Civil Española, Buenos Aires, Sudamericana.

" Montenegro, S. (2002). "La Guerra Civil española y la política argentina.", Tesis doctoral, Universidad Complutense de Madrid.

"Núñez Díaz-Balart, M. (2006). La disciplina de la conciencia: las Brigadas Internacionales y su artillería de papel. Barcelona: Flor del Viento.

» Osorio, E. (2012). La Capitana. Madrid: Siruela.

"Piemonte, V. A. (2016). "Las prácticas políticas del Partido Comunista de la Argentina ante la guerra civil española y su relación con la Internacional Comunista", Historia Contemporánea 52: 179-209.

»Pieper Mooney, J. E. (2013). “El antifascismo como fuerza movilizadora: Fanny Edelman y la Federación Democrática Internacional de Mujeres (FDIM)", Anuario IEHS 28: 207-226.

"Quijada, M. (1991). Aires de república, aires de cruzada: la guerra civil española en Argentina. Barcelona: Sendai.

"Rein, R. (2016). "Desafiando la política oficial: el antifranquismo en la Argentina", en Raanan Rein y Joan Maria Thomàs (eds.). Guerra Civil y Franquismo: Una perspectiva internacional. Zaragoza: Editorial de la Universidad de Zaragoza, pp. 99-129.

"Rohr, I. (2008). The Spanish Right and the Jews, 1898-1945: Antisemitism and Opportunism. Brighton, Sussex University Press. 
»Romero, L. A. (2011). "La Guerra Civil Española y la polarización ideológica y política: La Argentina 1936-1946", Anuario Colombiano de Historia Social y de la Cultura, Vol. 38, No. 2: 17-37.

»Rosenstone, R. (1969). Crusade of the Left: The Lincoln Battalion in the Spanish Civil War. New York: Pegasus.

» Rothenberg, J. (1980). "The Jewish Naftali Botwin Company." Jewish Frontier 47/4: 14-19.

»Rueda Laffond, J. C. (2019). "Judíos, comunistas e interbrigadistas: intersecciones y ambivalencias en los años treinta desde un enfoque transnacional", Revista Brasileira de Historia, Vol. 39, No. 82: 241-263.

»Sánchez Cervelló, J. y Agudo Blanco, S. (eds.). (2015). Las Brigadas Internacionales: nuevas perspectivas en la historia de la Guerra Civil y del exilio. Taragona: URV.

» Schenkolewski-Kroll, S. (1999). "El Partido Comunista en la Argentina ante Moscú: deberes y realidades, 1930-1941", Estudios Interdisciplinarios de América Latina y el Caribe (EIAL), vol 10:2, 91-107.

»Sichon, G. E. (1998). "Les voluntaires juifs dans la guerre civile en Espagne: chiffres et enjeux." Les Temps Modernes 44/507: 46-62.

"Singerman, B. (1981). Mis dos vidas. Buenos Aires: Tres Tiempos.

» Smith, J. y Johnston, H. (eds.). (2002). Globalization and Resistance: Transnational Dimensions of Social Movements. Lanham, MD: Rowman \& Littlefield.

» Sugarman, M.(2014). "AgainstFascism-JewswhoservedinThe International Brigade in the Spanish Civil War," https://www.jewishvirtuallibrary.org/ jsource/History/spanjews.pdf, recuperado el 25/11/2019.

» Tarcus, H. (2000). “Historia de una pasión revolucionaria. Hipólito Etchebehere y Mika Feldman, de la reforma universitaria a la guerra civil española." El Rodaballo. Revista de Política y Cultura, No. 11/12: 38-51.

» Timerman, J. (1982). Preso sin nombre, celda sin número, Buenos Aires: El Cid.

»Zaagsma, G. (2011). "Die Botwin Kompagnie." In Enzyklopädie jüdischer Geschichte und Kultur, ed. Dan Diner. Band 1: 393- 7. Stuttgart, Weimar: Metzler.

»Zaagsma, G. (2017). Jewish Volunteers, the International Brigades, and the Spanish Civil War. London: Bloomsbury. 